\title{
Un arte de memoria rimado en el Epítome de la Elocuencia Española, de Francisco Antonio de Artiga
}

FERnANDo R. DE LA FLOR

I.B. «Fray Luis de León». Salamanca.

Cien años después de ser emitidos, los juicios de Menéndez Pelayo sobre el tratado de retórica de Francisco Antonio de Artiga, publicado por vez primera en las postrimerías del siglo XVII (Huesca 1692), parecen todavía difícilmente revocables. En efecto, la importancia de la obra toda del polifacético escritor oscense ha caído en un generalizado olvido, del que parecerá una extravagancia pretender sacarla. Su libro más editado, este Epítome de la eloqüencia española. Arte de discurrir y hablar con agudeza y elegancia en todo género de assumptos..., «absurdo y chistoso [...] degeneración pedestre de la escuela conceptista» ${ }^{1}$, representa, sin duda, el punto extremo de una decadencia gestada a todo lo largo del siglo XVII.

Situada al final de una larga tradición, que en la época de su aparición ofrece claros signos de agotamiento y repetición, la retórica de $\mathrm{F}$. A. Artiga se constituye antes como un pequeño prontuario que repertoriza lo retórico, que como una obra que prolongue el esfuerzo de for-

1 M. Menéndez Pelayo, Historia de las Ideas Estéticas en España, vol. 2, Madrid, A. Pérez Dubrull, 1883-1923, n. 536. 
malización que, teóricamente, preside la historia misma de la técnica a la que se dice servir con su publicación.

Sin embargo, pese a estas evidencias, puede resultar pertinente revisar la ubicación de esta obra, que actúa como un verdadero revulsivo para los intentos más modernos de construir una verdadera ciencia literaria. Moderna retórica esta última, que se proyecta como seculariza$\mathrm{da}$, belletristica, manifestando su distanciamiento de la Oratoria sagrada y del modelo rígido ciceroniano. Retórica novatora que, como ha visto D. Abbot ${ }^{2}$, es impulsada, ya en la época ilustrada, por teóricos como Mayans, Capmany o Jovellanos.

Desde otra perspectiva más, que es la que ahora nos va a interesar, esta retórica de Artiga es destacable, en cuanto que mantiene una estructura heredada, alguna de cuyas partes estaba a punto de caer en el total desuso; convirtiéndose así el libro en un depósito arqueológico y en el vehículo, como veremos, de unos saberes amenazados por la nueva época y por el pensamiento teórico que la formaliza.

Si fue su propio crédito - extendido entre un cierto tipo de público necesitado de una formación oratoria- el que hizo posible que el Epítome... fuera de los textos de retórica que mayor difusión alcanzaran a lo largo del siglo XVIII (con ediciones en 1692, J. Lorenzo de Larumbe, Huesca; 1725, s.i., Madrid; 1726, A. Burguete, Pamplona; s.a., F. Rodríguez, Madrid; 1737, F. Rodríguez, Madrid; s.a. (pero 1747), s.i., Madrid; 1750, M. Martí, Barcelona; 1760, M. Martí, Barcelona; 1770, Vda. de Martí, Barcelona; 1771, A. Mayoral, Madrid; 1792, s.i., Huesca) ${ }^{3}$, se debió fundamentalmente a dos aspectos que le confieren

2 «Retórica y Elocuencia: The Evolution of Rhetorical Thought in Eighteenth Century Spain», The Quarterly Journal of Speech, 64, 1978, 295-303. También: M. Baquero Goyanes, «Prerromanticismo y Retórica: Antonio de Capmany», en Homenaje ofrecido a Dámaso Alonso, I, Madrid, Gredos, 1960, 171-89; y, más allá del marco temporal que nos hemos impuesto: A. Soria, «Notas sobre Hugo Blair y la retórica española en el siglo XIX», en Estudios sobre Literatura y Arte dedicados al profeșor Emilio Orozco Díaz, III, Granada, Universidad de Granada, 1979, 363-88.

3 Para las ediciones del Epitome, cf. Latassa, Biblioteca Antigua y Nueva de escritores aragoneses, Zaragoza, Calisto Ariño, 1884, págs. 150-1; J. Simón Díaz, Bibliografía de la Literatura Hispánica, VI ${ }^{2}$, Madrid, C. S. I. C., n. ${ }^{\circ}$ 916-29 y F. Aguilar Piñal, Bibliografía de Autores españoles del siglo XVIII, I, Madrid, C. S. I. C., 1981.

Para mayores detalles sobre las vicisitudes sufridas por alguna de estas ediciones, véase la Memoria de licenciatura de J. Castán Lanaspa, El Epítome de la elocuencia, de F. A. de Artiga, ejemplar mecanografiado en la Biblioteca de Letras de la Universidad de Salamanca (sig: T/663). 
un valor peculiar desde la perspectiva de nuestro tiempo ${ }^{4}$. Por un lado, su formulación atrevida, extravagante, que tiende a convertir el dispositivo académico de la retórica en un recetario novedoso en su factura; de otro, el hecho de que en sus páginas se conserva la reliquia de un saber apenas modificado desde los tiempos de Cicerón: la mnemotecnia. Esta alianza contradictoria de innovación y tradicionalismo convierte el Epítome de Artiga en un discurso situado al límite mismo de las tensiones que difícilmente puede sostener un texto dedicado a la pedagogía, siendo por ello mismo atractivo para un gran número de sus contemporános, que todavía buscaban en la originalidad la razón de ser de la lectura ${ }^{5}$.

\section{El proyecto mnemotécnico en el Epítome de la elocuencia española}

Todo el Epítome se encuentra inscrito en un proyecto mnemotécnico: «Mas sírvame de disculpa/ - escribe Artiga - mi fin que ha sido abreviar/ en la mía a todas juntas/ y en nuestra lengua española/ y en verso; porque ésta ayuda/ la memoria.... ${ }^{6}$. Se trata, pues, de una obra para su memorización en una suerte de vademécum, con aplicaciones a un variado repertorio de situaciones que provienen del mundo de la conversación, del trabajo epistolar, del ars praedicandi... De esta inscripción suya en la psicología pedagógica provienen las dos marcas fundamentales que estructuran el libro todo: su disposición dialógica, en la línea de algún otro tratado español de mnemotecnia ${ }^{7}$, y su carácter rimado ${ }^{8}$.

4 Esta valoración que proponemos se encuentra muy lejos de la descalificación absoluta y poco científica con que trata el Epítome, entre otros, A. Martí, La preceptiva retórica española en el Siglo de Oro, Madrid, Gredos, 1972 págs. 306-8, cuando escribe: «Se trata de una obra flojísima con unas ideas extrañas y tan raras que nos maravilla cómo pudieran ocurrírsele al autor tales cosas. Es el último grito de un siglo en el terreno de la retórica: ¡bien lamentable por cierto!».

5 Para este tema en la cultura barroca, cf. J. A. Maravall, «Novedad, invención, artificio», en La cultura del Barroco, Barcelona, Ariel, 1980, págs. 453-99.

6 Cito en adelante por la edición de Barcelona, M. de Marti, 1770.

7 Recientemente, V. G. de la Concha ha dado a conocer lo que constituye el más antiguo arte de memoria conocido en castellano: Dichos y hechos de los filósofos antiguos, de Alexandro Magno, en un Arte de memoria (h. principios del XV). La obra se estructura en buena parte en torno al debate de las tres potencias, memoria, entendimiento y voluntad (cf. V.G. de la Concha, «Un arte memorativa castellana», en Serta Philologica ad Honorem F. Lázaro Carreter, II, Madrid, Cátedra, 1983, 187-97).

8 Aquí el precedente es Arias Montano, quien en su tratado en verso Rhetoricorum 
Retórica para ser memorizada fácilmente, en el Epítome no pueden dejar de conservarse aquellas cinco operaciones principales que definían la tecné retórica, desde sus primeras formulaciones debidas a Cicerón, a Quintiliano, al anónimo redactor del Ad Herenium y, atrás en el tiempo, al mismo Aristóteles: inventio, dispositio, elocutio y, las más inestables desde el punto de vista de su conservación en el dispositivo retórico, memoria y pronuntiatio. Todas ellas se hallan vulgarizadas, pero sustancialmente fieles a una determinada tradición expositiva, en el texto de Artiga.

Es precisamente esta fidelidad con que Artiga mantiene una visión de la retórica ya por entonces gravemente cuarteada, la que llena su libro de unas extrañas resonancias que enseguida vamos a tratar de elucidar.

P. Kuentz ha escrito recientemente que «la imagen que nos propone la historia de la retórica es la de su deterioro» ${ }^{9}$. Desmantelamiento, en efecto, de la retórica clásica, que se ha operado, primero, sobre los elementos más materiales del sistema: la pronuntiatio y la memoria, desplazadas ambas por la reconversión del ars dicendi en ars scribendi, por la proliferación del libro y el paralelo debilitamiento de la palabra, de la prédica. Estas dos partes de la elocuencia a las que antaño les estaba confiada la salvaguardia memorística de las figuras del discurso ${ }^{10}$ y la puesta en escena - actio- del mismo, respectivamente, se encuentran ya completamente atrofiadas en el siglo XVII ${ }^{11}$, quedando relega-

libri IIII, Antuerpiae, Christoph. Plantinus, 1569, inserta un pequeño tratado de mnemónica (cap. XXI-LIII).

9 P. Kuentz, «La retórica o la puesta al margen», en AAVV, Investigaciones retóricas, II, Barcelona. Tiempo Contemporáneo, 1970, pág. 186. También Genette, Figures III, París, Seuil, 1972, 22, ha visto en esta simplificación de toda la retórica a la elocutio una característica de la época clásica. Jakobson, en este sentido, todavía restringe más el campo hasta reducir toda tropología al par metáfora/metonimia.

10 Función esta de la memoria que aparece sobrevalorada en el texto de Artiga: «Y todos [invención, disposición, elocución] como cristales/ (según me decís) se quiebran/ si no les da la Memoria/ ser, duración y firmeza» (pág. 393).

11 La reducción drástica de toda la retórica a la elocutio tiene, en la tradición española, el antecedente del Vives de De ratione dicendi (1536). La Agudeza de Gracián, como ha visto B. Pelegrín, «La retórica ampliada al placer», Diwan, 8-9, 1980, págs. 40-2, representa la culminación de este proceso depurativo. No entendemos, desde este punto de vista, la apreciación de Correa de que el Epítome de Artiga se encuentre influido por la Agudeza y Arte de ingenio (cf. "prólogo a las Obras Completas de B. Gracián, Madrid, Aguilar, 1944, CXXXIV). 
da su aparición dentro del ars praedicandi, que las mantendrá obstinadamente en nombre de la finalidad que persigue: el movere, conmover las almas.

La retórica de Artiga es la última en su tiempo en mantener la estructura intacta del viejo sistema caído en el descrédito. La inclusión en ella de un Arte de la memoria, sujeto a toda la tópica que sobre este saber se había ido generando desde las secciones correspondientes del De oratore ciceroniano ${ }^{12}$, las Institutio de Quintiliano o en las referencias incluidas en las obras de Tomás de Aquino (Summa Theologiae II, 2, 49; Comentario al De memoria et reminiscentia de Aristóteles) ${ }^{13}$, Iacopo Ragone da Vicenza (Artificialis memoriae regulae) y del San Agustín de Las Confesiones (lib. X) ${ }^{14}$, supone un afán vulgarizador en un área marginal y marginada ${ }^{15}$.

Voluntad de perseguir el asombro, la curiosidad, cierta heterodoxia, que ha acompañado siempre toda formalización de una mnemotecnia, hasta el punto de convertir el tratado de Artiga en una operación de rescate de una técnica intelectual casi secreta ${ }^{16}$. Lo que se ma-

Sobre la mnemotecnia en Cicerón, cf. F. A. Yates, «The Ciceronian Art of Memory», en Medioevo e Rinascimento, studi in onore di B. Nardi, Firenze, Sansoni, 1956, 878-881.

13 Cf. un estudio de estas obras desde el punto de vista mnemotécnico en F. A. Yates, El arte de la Memoria, Madrid, Taurus, 1974, págs. 43-69.

14 Una versión «filosófica» del Ars Mnemónica puede encontrarse, además de en Aristóteles (De memoria...), en Platón (Timeo, IV, 26b), Séneca (De beneficiis, III, 2-5) y Alberto Magno (De bono, IV, 2). El «Scio plerosque Graecos, qui de memoria scripserunt», con que se abre la sección dedicada a la memoria artificial en la Rhetorica ad Herennium (III, 23), evidencia la presencia de esta técnica en la cultura griega, tema que ha sido tratado por: L. A. Post, «Ancient Memory Sistems», Classical Weekly, 15, 1932, 32-65; P. Laurad, «La mnémo-technie des anciens», en Manuel des études grecques et latines, París, Les Humanités, 1933 y J.P. Vernant, «Aspects mythiques de la mémoire et du temps», en Mythe et pensée chez les Grecs, París, Maspero, 1965.

15 Vindicación de la memoria que Artiga emprende no de modo solitario en el ámbito europeo, ya que los textos de J. Brancaccio, Ars Memoriae Vindicata, Palermo, Heredi di Perin Libraro, 1702; las Disertaciones Históricas de J. Custures, Mallorca, Miguel Capó, 1700; M. D'Assigny, The Art of Memory, T. Vautrollier, London, 1697; C. Knitte, Via regia ad omnes scientias et artes..., Pragae, J. C. Laurer, 1687, y J. B. Ptholomeo, Philosophia mentis et sensum..., s.l. [¿Roma?], s.i., 1696, van a asegurar la pervivencia de esta vieja técnica en el mundo cartesiano.

16 Con el Epítome de la elocuencia, Artiga se propone hacer una exposición «llana» de un artificio intelectual hasta entonces de uso muy restringido. Necesidad de acla- 
nifiesta en el libro es un esfuerzo repertorizador de datos dispersos, de conocimientos que la práctica estaba comenzando a desechar, y es así como el Epitome de Artiga juega un papel fundamental, traspasando de un siglo al otro, del XVII al XVIII, y entre una extensa capa de lectores de su obra, un tipo de disciplina intelectual que sin su concurso y el de otros (Ortiz, Memoria, entendimiento, voluntad, Sevilla 1677; Ximenez Patón, Mercurius Trimegistus, Madrid 1621), hubiera terminado, sin duda, por desaparecer.

Si queremos atender a una versión peyorativa de esta función de puente hacia otra época que el Epitome ejemplarmente cumple, las palabras de Ferrer del Río en su Discurso sobre la Oratoria española en el siglo XVIII: «El siglo XVII no transmitía al XVIII más que escoria» ${ }^{17}$, pueden parecer particularmente apropiadas referidas al objeto de nuestro estudio. Pero desde el punto de vista de la aparición y desaparición de unos saberes que han incidido en la evolución compleja de una cultura, el Epítome de la elocuencia de Artiga ocupa una posición clave.

Es de este modo, paradójico si se quiere, como el mantenimiento en una retórica de finales del XVII de un tratado de mnemotecnia evidencia, por un lado, una vocación anticuada y retardataria en la concepción de esa disciplina, pero por otro constituye un magnífico ejemplo de la vitalidad que mantienen ciertos paradigmas, contrarios ya en todo a la nueva situación de la ciencia y del mundo secularizado, en medio del cual son convocados. Presencia amortiguada, si se quiere, con la que la mnemotecnia figura junto a otros corpus doctrinales, teñidos en general de heterodoxia - como la astrología judiciaria, la cábala...-, que harán una de sus últimas apariciones en la escena cultural en el primero de sus revival desde el Renacimiento: el que tiene su lugar en los primeros decenios del siglo XVIII ${ }^{18}$.

rar, hacer saber, difundir, que va a presidir un siglo --el XVIII- en cuyos umbrales se sitúa esta obra: «Cuyo artificio verás/ explicado, no en aquella/ manera, que Lulio, Alstedio, / Bauxio, y Eschenkilio enseñan / de tanto enigma, anagrama, / línea, triángulo, y rueda / que no son proporcionadas / para todas las cabezas» (pág. 400).

17 En Discursos leídos en las recepciones públicas que ha celebrado desde 1847 la R. A.E., I, Madrid, Imprenta Nacional, 1860, pág. 375.

18 Sobre el pensamiento mágico y heterodoxo en los comienzos de la Ilustración, puede verse el libro de I. M. Zavala, Clandestinidad y libertinaje erudito en los albores 
En esta posición charnela de 1692 es inevitable que el Epítome contenga una mirada retrospectiva a los cerca de trescientos años de mnemotecnia española, que se abren con los Dichos y hechos de los filósofos antiguos de A. Magno, con un Arte de Memoria ${ }^{19}$. De este modo, en su sección dedicada a la mnemónica, el Epítome cumple el cometido de vulgarizar los ciertamente más complejos tratados de Sánchez Ciruelo (De arte memorandi, Alcalá, 1528); Aguilera (Ars memorativa, Salamanca 1536); Velázquez de Acevedo, (Fénix de Minerva y Arte de Memoria, Madrid, 1626) o Gutiérrez Godoy (Disputationes philosophicae ac Medicae super libros Aristotelis de memoria et reminiscentia, Jaén, 1629) ${ }^{20}$, de todos los cuales vendrá a realizar una síntesis, en la que se ha eliminado la inmensa casuística que presenta el sistema mnemonicum, sustituido por un breve manual de consejos para afianzar una cierta memoria artificial:

Para mi estudio lo hice

recogiendo los selectos

preceptos de grandes libros

en éste que es tan pequeño (pág. 10).

La publicación de este tratado de mnemónica y su reedición sistemática a lo largo del siglo XVIII avanza en perspectiva una serie de fenómenos en torno a los cuales se va a ir solidificando, a veces por reacción, el pensamiento ilustrado. Cierto renacer del lulismo en los primeros años del siglo XVIII ${ }^{21}$, la polémica contra Feijoo en la cuestión del

del siglo XVIII, Barcelona, Ariel, 1978 y mi artículo: «Mnemotecnia y hermetismo luliano en el primer XVIII español», El Crotalón, 2 (en prensa). Para otro punto de vista más amplio sobre el tema, cf. G. Carnero, La cara oscura del Siglo de las Luces, Madrid, Fundación March, 1983.

19 Vid. supra, n. 7.

20 Véanse referencias a estas obras, y, en particular, a la de Velázquez de Acevedo, en mi artículo «Mnemotecnia y Barroco: el Fénix de Minerva, de Juan Velázquez de Acevedo», Anales Salmantinos de Filosofía, XII (1985), 183-203.

21 Originado en parte por la edición Mainz de la Opera Omnia de Lull (1721-1742), el lulismo español del XVIII es avivado desde Mallorca (con el centro lulista del Colegio de N. ${ }^{a}$ S. ${ }^{a}$ de la Sapiencia, donde se hace, en 1744, una edición de la Opera parva) y mantenido por la existencia de cátedras lulistas en Salamanca y Valencia. La bibliografía sobre el tema en general es muy amplia, pero, en concreto, las relaciones entre mnemotecnia y lulismo en los comienzos del siglo XVIII han sido revisadas por J. Carreras y Artau, De Ramón Lull a los modernos ensayos de formación de una lengua universal, Barcelona, Ivern, 1946. 
Ars Combinatoria ${ }^{22}$ y la aparición en 1735 del texto con que, eventualmente, se cierra la proyección histórica del Ars en España: la obra de Nolegar Giatamor (Girolamo Argenti) el Assombro elucidado de las ideas o Arte de Memoria; todos estos fenómenos se encuentran vinculados al breve tratadito de Artiga, y con él expresan la imposible pervivencia de una técnica intelectual cuya dudosa evolución (de una operación retórica a una magia, pasando por una instrumentación piadosa) aparece ya como sentenciada, desde el punto de vista de la razón y de la historia: «Dudo - escribe Feijoo- de lo que se puede conseguir con el Arte de la Memoria [...] De la Arte Magna de Lulio, sin perplexidad alguna, pronuncio que es enteramente vana, y de ninguna conducencia para el fin que su Autor propone») ${ }^{23}$.

\section{Memoria artificial y oratoria sagrada}

La inclusión de un Arte de la Memoria, casi autónomo del contexto general en que se presenta, en una retórica de finales del siglo XVII como es el Epítome de la elocuencia, proviene de la compleja evolución que la llamada memoria artificial corre en el seno de dos sistemas diferentes, pero que cierta práctica tenderá a reunir: en primer lugar, la mnemotecnia, como hemos visto, se presenta como parte integrante del dispositivo retórico, preservándolo en cierta manera, y contribuyendo así a su eficacia indiscutible. Por otro lado, y esto ya desde el tiempo en que los retóricos escolásticos, siguiendo al Aristóteles de De memoria et reminiscentia... y a sus comentaristas Alberto Magno (De bono) y Tomás de Aquino (In Aristotelis. De sensu et sensato) ${ }^{24}$, comenzaron

Los textos de Feijoo - Cartas XX, XXI y XXII de las Eruditas - sobre el Ars Magna luliana, desencadenan, en 1742, una polémica, en la que intervienen seguidores de Lulio, y entre ellos: B. Fornés (Liber apologeticus Artis Magnae B. Raymundi Lulli, Salamanca, Eugenio García Honorato, 1746); F. de Soto y Marne (Reflexiones crítico-apologéticas sobre las obras de Feijoo, Salamanca, Eugenio García Honorato, 1748-1749) y A. R. Pascual (Examen de la Crisis de el Rmo. Padre Maestro D. B. Gerónimo Feijoo, Madrid, Lorenzo Francisco Mojados, 1749).

Carta XXII «Sobre el Arte de Raymundo Lulio», en Cartas Eruditas.

Una síntesis de todos estos textos, en sus aspectos mnemotécnicos, la realiza tempranamente Paepp en su Artificiosae memoriae fundamenta ex Aristotele, Cicerone, Thoma Aquinate aliisque praestantissimis doctoribus, Lyon, Bartholomeum Vincentium, 1619. 
a adaptar la retórica a un uso piadoso ${ }^{25}$. La Memoria aparece como memoria de imágenes y loci — vistas persuasivas del cielo y del infierno- ${ }^{26}$. Esta versión virtuosa hace que, junto a la Prudencia y la Voluntad, la Memoria aparezca convocada a la hora de construir el lenguaje de lo sagrado. Todo el dispositivo retórico se ajusta minuciosamente para construir y avalar el sermón, la oratio cristiana, pero será precisamente en su parte IV o Memoria donde muchas de las retóricas al uso a lo largo del siglo XVII se conviertan en retóricas cristianas. Y ello principalmente por el uso de una imaginería que proviene del repertorio iconográfico fundado en la tradición cristiana ${ }^{27}$.

En el uso que la primitiva escolástica hacía de los procedimientos mnemotécnicos, repertorizados en la anónima retórica Ad Herennium, podemos comprobar cómo las intenciones espirituales se visten con similitudes corporales, facilitando así el paso a la existencia independiente de una memoria artificial, que se sitúa a caballo entre la propia retórica de signo clásico, a la que sin duda pertenece, y la ética, en cuyo ámbito pretende radicar el sentido de su actuar sobre el mundo psicológico ${ }^{28}$.

25 En este sentido, la Ecclesiasticae Rhetoricae, Olyssipone, A. Riberius, 1575, de Luis de Granada es el primer paso hacia la construcción de un corpus retórico dirigido al orador sagrado. Hay que recordar la definición que, pocos años después de la aparición de la obra de Luis de Granada, da B. Jiménez Patón: «La Rhetorica es un arte que enseña a adornar la oración» (Elocuencia española en arte) Toledo, Thoms [sic] de Guzmán, 1604, pág. 148.

26 Se trata en realidad, como escribe Boncompagno de Signa en su Rhetorica Novissima, de «recordar con asiduidad los gozos invisibles del Paraíso y los tormentos eternos del Infierno» (cit por F. A. Yates, El Arte..., 77), y según Ortiz: «La memoria del Infierno es tan provechosa que la mayor recomendación della es el darla a conocer. Descienden los vivos al Infierno dize por boca de David el Espíritu Santo, con que sólo el descender allá con la Memoria es tan eficaz y tan provechoso remedio que, según la sentencia del Santo, es bastante para librarnos de él» (Memoria, Entendimiento y Voluntad. Empresas que enseñan y persuaden su buen uso en lo moral y en lo político, Sevilla, Juan Francisco de Blas, 1677, pág. 20. Villava, en el prólogo al lector de sus Empresas espirituales y morales, Baeza, Fernando Díaz, 1613, defiende la eficacia de estas imágenes mnemotécnicas: «Fundado un pensamiento en una similitud cobra fuerça de alentar y recrear el entendimiento, y bien se ve lo que un símil vivo recrea y adorna una oración, y cuán bien se persuade lo que al vivo se representa (fol. 3 r.).

27 Como es evidente en el tratado de F. Panigarola, $L$ 'art de prescher et bien faire un sermon avec la mémoire locale et artificielle, ensemble L'Art de mémoire de H. Marafiote, París, G. Chappis, 1604.

28 Es curioso constatar el esfuerzo realizado por los oradores sagrados en separar la mnemotecnia del mundo de la retórica e integrarla en la órbita de las virtudes mora- 
Ha sido V. G. de la Concha ${ }^{29}$ quien ha señalado en el primer tratado de mnemotecnia conocido en España -Dichos y hechos...- esa gravitación hacia la conversión del lector, que guía el Arte y su conexión, fuertemente afianzada, con los planteamientos del ars praedicandi. A lo largo de los siglos XVI y XVII se va construyendo el edificio de una retórica vertida a lo divino. Y dentro de ella la memoria, la memoria artificial, tiene un papel decisivo a la hora de estructurar los procesos de oración.

La vinculación existente entre mnemotecnia y el procedimiento, específico dentro de la ascética jesuística, de la compositio loci, es una constante en la literatura espiritual del Siglo de Oro ${ }^{30}$, y ello ha sido analizado recientemente en los casos particulares de Teresa de Jesús ${ }^{31}$ y de Gracián ${ }^{32}$.

En torno a esta práctica de la vista del lugar ignaciana, cristalizan, como he demostrado en otra parte ${ }^{33}$, las diferentes operaciones de re-

les, como parte de la Prudencia: «No faltó quien quiso al juicio hacerlo sesta parte de la Retoria [sic] con hallarse tan junto con las demás, que casi ninguna es sin él por ser para todos necesario, y con este poco fundamento también hacían la memoria parte de la Retórica, lo qual es falso como emos probado, y porque es potencia del alma mediante la qual todas las facultades se desprenden, y no parte dellas...» (B. Jiménez Patón, Mercurius Trimegistus, Madrid, Petro de la Cuesta Gallo, 1621, cap. XXIV, de la Memoria, pág. 146).

29 «Un arte memorativa castellana...», pág. 190.

30 Sobre el tema de la articulación de «la vista» o «composición viendo el lugar» de los Ejercicios ignacianos y su conexión con la memoria artificial, cf. R. Barthes, Sade, Loyola, Fourier, Caracas, Monte Ávila, 1977, págs. 58-62 y mi trabajo: «La Compañía de Jesús: imágenes y memoria», Hiperión 3, 1979, 62-72, El tema, en sus implicaciones con las artes plásticas -imaginería, pintura...- ha sido tratado por S. Sebastián, Contrarreforma y Barroco, Madrid, Alianza, 1981, págs. 62 y ss. En un sentido más general $c f$. J. R. Spencer, «Ut Rhetorica Pictura», Journal of the Warburg and Courtland Institutes, 20, 1957, 26-44.

31 Véanse los estudios de A. Egido, «La configuración alegórica de El castillo interior», Boletín del Museo e Instituto Camón Aznar, 10, 1982, 69-94, y J. F. Chorpenning, «The Literary and Theological Method of the Castillo interior», Journal of Hispanic Philology, III, 2, 1979, 121-34.

32 cf.: F. R. de la Flor, «El Comulgatorio de Baltasar Gracián y la tradición jesuítica de la compositio loci», Revista de Literatura, 85, 1981, 5-18 y «El Comulgatorio de Baltasar Gracián: una retórica de la piedad», Studia Philologica Salmanticensia, 7-8; 1984, 269-302.

33 «La literatura espiritual del Siglo de Oro y la organización retórica de la Memoria», Revista de Literatura, 90, 1983, 39-85. 
ferencia mnemotécnica. La meditación por imágenes - formadas bajo los preceptos de las secciones de mnemónica que en las retóricas del momento siguen fielmente los preceptos de Quintiliano, Cicerón y el anónimo redactor del $A d$ Herennium - alcanza una máxima difusión en el seno de obras como las Evangelicae Historiae Imagines de J. Nadal, el Epistolario del beato Juan de Avila o La conquista del espiritual y secreto reino de Dios de fray Juan de los Ángeles.

Los elementos dispersos de toda esta tradición los encontramos reunidos en el Epítome de la elocuencia de Artiga, pero, de un modo mucho más concreto, el tratado IV de la obra nos remite a todas las retóricas que, bajo el signo de una utilización piadosa, fueron apareciendo a lo largo del siglo XVII ${ }^{34}$. Es en obras como las del cercano a Artiga, Francisco Ameyugo (Retórica sagrada y evangélica ilustrada con la práctica de diversos artificios retóricos para proponer la palabra divina, Zaragoza, 1667) donde la memoria artificial se propone como un recurso para dotar a la palabra sagrada de toda su impresividad y eficacia: «Dispuesto el sermón con el orden, hermosura y sal que hemos notado hasta aquí, resta el sacarlo a la luz representándole bien. Para este fin, la primera diligencia es tomarlo bien de memoria...» (pág. 69).

Estas obras teóricas de la pedagogía cercana al espíritu de la Ratio studiorum ${ }^{35}$ retoman las normas mnemotécnicas clásicas e infunden a su lenguaje una dirección que afecta a la vida moral, objetivo último

34 Para Artiga, desde una perspectiva amplia, es toda la elocuencia la que se encuentra incluida en un proyecto piadoso:

La eloqüencia es un concepto
de la Unitrina Assonancia,
que en tres partes igual forma
la causa de tantas causas (pág. 426).

35 Como las obras de Castro, De Arte Rhetorica, Córdoba, Francisco de Cea, 1611, que trata de la memoria artificial en su «Dialogus quartus», págs. 104-42; Escardo, Rhetorica Chistiana, Mallorca, Gabriel Guasp, 1647, cap. 98, págs. 487-99 o Terrones Aguilar del Caño, Arte o instrucción... Partes que ha de tener el predicador evangélico, Granada, B. de Lorenzana, 1617, cap. 6, págs. 157 ss. Para el estudio del lugar que ocupa la retórica, que a partir de 1586 vertebra el modelo pedagógico de la Ratio, cf. A. Martí, La preceptiva retórica española en el Siglo de Oro, Madrid, Gredos, 1972, págs. 234 y ss.; Rico Verdú, La retórica española de los siglos XVI y XVII, Madrid, CSIC, 1973, págs. 57-64 y M. Matilla, «La Ratio Studiorum de los jesuitas», Durius, Bolẹtín de Estudios Clásicos, 3, 1975, 247-55. 
de la potenciación de los recursos psicológicos en la esfera de lo individual ${ }^{36}$.

Es desde esta perspectiva desde donde mejor podemos entender la orientación religiosa que todo el Epítome conserva, y en especial su tratado IV, del que venimos hablando. Dirigido, como ha visto J. Castán ${ }^{37}$, a un público mayoritariamente formado por sacerdotes, su utilidad se revela vinculada a la construcción del sermón, y, dentro de él, a la atención particular por los loci e imagines relacionados con la Historia Sagrada:

\author{
$\mathrm{Y}$ assí el Arte de Memoria, \\ cuyo exercicio se emplea \\ en acordar lo que hizo \\ la Divina Providencia, \\ también se funda en imágenes (pág. 432).
}

\title{
La referencia hermética
}

La dirección piadosa que hemos examinado, y que se sitúa en la línea de otras retóricas jesuíticas, no agota en modo alguno el haz de direcciones diversas que el tratado de la memoria artificial de Artiga viene a repertorizar. A la impostación de signo cristiano que sobre el primitivo saber retórico imprime Artiga se añaden multitud de referencias que construyen otra nueva imagen de lo que la mnemotecnia representa al final de una tradición que la ha desgastado. Sobrevive en la superficie del tratado, pese a su propósito desmitificador, una referencia hermética. Es, por otra parte, la obra toda de Artiga la que está sumida en un proyecto de construcción o, al menos, de conservación de unos saberes marginales: de un lado, los relacionados con la astrología judiciaria (Discurso de la naturaleza, propiedades, causas y efectos de Ios planetas, Huesca, 1681; Espejo astronómico, Huesca, 1684; Laberinto intelectual astronómico y elemental; Breve apología de los astró-

36 Ésta es la versión que de la utilidad de la memoria artificial hace Sebastián Izquierdo: «Usar de nuestras potencias naturales en las materias pertenecientes a nuestra salvación, a saber, de la memoria, poniendo delante el negocio de que avemos de tratar...» (Práctica de los Exercicios Espirituales de Nuestro Padre San Ignacio ,Roma, Tipographia Varesiana, 1675, pág. 8).

37 «El escritor oscense don Francisco Antonio de Artiga y su Epitome de la Elocuencia Española», Cuadernos de Aragón, 10-11, 1978, pág. 220. 
logos que yerran algunas predicciones; Libro del Áustrico Júpiter) ${ }^{38}$; por otro, su libro dedicado a los lenguajes ideográficos como revelación y sello de las verdades ocultas: Cartilla geroglífica de sabios.

El saber mnemotécnico mismo, como se han encargado de revelar Yates ${ }^{39}$, Rossi ${ }^{40}$ o Fagiolo Dell'Arco ${ }^{41}$, independizado ya en el siglo XVI de la específica técnica literaria que le vio nacer de espaldas a la práctica piadosa que el jesuitismo sancionaba, ostentará también, y simultáneamente, una marcada conexión con el pensamiento mágico. Al perder su contacto con la primitiva formulación de una técnica retórica, reaparece la mnemotecnia en la escena de la cultura humanística como instrumento de un saber total, de una pansofía. Esta nueva dirección es la que produce en España un texto como el Fénix de Minerva y Arte de Memoria de Velázquez de Acevedo ${ }^{42}$, que, alabado por Lope, adquirirá, sesenta años después de su publicación, una gran resonancia en las páginas del Epítome.

Como teatro del mundo, como aula para los arcanos, los sefirotas brunianos, las empresas y emblemas de filiación hermética, como escritura interior, la mnemotecnia vertebra gran parte del discurso del saber heterodoxo, que se constituía enfrentado a la ortodoxia cristiana y, finalmente también, en contra de la evidencia que suministraban la ciencia y la razón ${ }^{43}$.

38 Textos todos ellos, junto a la Cartilla geroglífica de sabios, citados por Latassa, sin constancia alguna de ser manuscritos o impresos. Tampoco se encuentran relacionados en la Bibliografía de J. Simón.

39 El Arte de...; Giordano Bruno y la tradición hermética, Barcelona, Ariel, 1983 y La filosofía oculta en la época isabelina, México, Fondo de Cultura Económica, 1982.

40 Clavis Universalis. Arti della memoria e logica combinatoria da Lullo a Leibniz, Bologna, II Mulino, 1983.

41 «Il giardino come teatro del mondo e della memoria», en La cittá effïmera e l'universo artificiale del giardino, Roma, Officina Ed., 1980, 125-41.

42 Sobre el Fénix de Minerva y todo el ambiente cultural que determina, en los albores del sigo XVII, un «renacimiento» de la mnemotecnia, véase mi artículo: «Mnemotecnia y Barroco...»

43 Pese a ello, la mnemotecnia figura en las especulaciones de Descartes - Regulae...-, Bacon -De argumentis scientiarum - y Leibniz - Nova methodus discendae..., que inauguraron el método científico. En el caso español en concreto, la mnemónica es considerada dentro del armazón epistemológico de la «nueva ciencia» en la obra de Sebastián Izquierdo, Pharus Scientiarum, Lugduni, C. Bourget et M. Liétard, 1659 y, sobre todo, en la de Pedro Bermundo, Arithmeticus Nomenclator omnes nationes ad linguarum..., Roma, Antonius Bretamus, 1653. 
Esta última - la razón, el impulso clarificador - continuamente invocada por Artiga, se abre paso trabajosamente en el seno mismo de los materiales de tradición hermetista que sucesivamente van haciendo su aparición, convocados en el capítulo IV del Epítome. Disección la que allí se realiza entre principios sicológicos, influencias, misterios, resonancias religiosas y de otros tipos, que no terminan nunca de asentar esta mnemotecnia del lado de una mera técnica pedagógica. Así, el «juzgo/ que algún gran secreto encierra [el ars mnemónica]», con que se abre el Epítome, lo clausura también a la exposición, pese a ser su declarado fin el de venir a introducir las luces en un arte pretendidamente misterioso porque «la ocultan y la pertrechan/ con tanto escuadrón de enigmas/ que es imposible emprenderla» (pág. 379).

La antigua pretensión luliana de configurar un sistema -la Combinatoria - capaz de estructurar - de conferir un lugar, un locusa toda la diversidad de los entes, dotados de sus imagines correspondientes, percusivas para la memoria ${ }^{44}$, reaparece aquí, en el Epítome, sometida a una simplificación que casi constituye una parodia. El ars rotunda, las ruedas lulianas que presentan conexiones astrológicas, son evocadas en el texto de Artiga desprovistas por completo de la densidad simbólica que da sentido al Ars magna de Lulio. Zodiaco y mnemotecnia aparecen, de nuevo, así vinculados en un único proyecto, que pondrá al hombre en conexión con el universo y, a través de él, con la Idea última que es su causa:

Porque dentro la Memoria todos los cielos rodean, todos los astros relucen, brillan todos los Planetas (pág. 395).

Es la tradición hermética, dentro de la cual se encuentra incluido el artificio luliano, la que presta un cercano sentido a muchas páginas del Epítome de la elocuencia. Lulio mismo, a quien en todo sigo, como confiesa Artiga ${ }^{45}$, es situado junto a Egipcios, Arithméticos y sabios clásicos, en una misma secuencia que sirve para evidenciar que las verdades instituidas por revelación permanecen secretas para el vulgo. Ins-

44 Sobre los procesos de construcción de imágenes mnemotécnicas, tal y como se formulan en el neoplatonismo renacéntista, $c f .:$ P. Rossi, «La costruzione delle immagini nei tratti di memoria artificiale del Rinascimiento», en Umanismo e Simbolismo. Atti del IV convegno internazionale di studi umanistici, Padova, E. Castelli, 1958.

45 Epítome..., pág. 415. 
talando así al Epítome en una falla de la historia, en el paso mismo para la diafanía universal de unos saberes, por fin al alcance de todos. Ya no se trata para Artiga de una técnica al servicio de los sabios, sino que la mnemotecnia del Epítome se constituye como divulgadora de unos principios que puedan convertir al hombre sin estudios, al ignorante incluso - y con poco esfuerzo- en el posesor de la eterna memoria de todas las cosas.

Por todas partes, diseminadas en este tratado de mnemotecnia insertado en el Epítome, se encuentran las ruinas y supervivencias de la gran tradición hermética renacentista: el cabalismo cristiano ${ }^{46}$, el Ars notoria, cierta simbología de matiz alquímico... Junto a todo ello, los restos también de un sistema mnemonicum; fragmentos de teorías en gran medida desechadas, que aparecen situadas, como en una correa de transmisión, entre los dos corpus de mayor solidez conceptual dedicados al arte en España: el Fénix de Minerva de Velázquez de Acevedo, publicado en 1626, y el Assombro elucidado de las ideas de Girolamo Argenti, en 1735 .

Cuando Feijoo, èn 1742 y en sus Cartas eruditas XXI ( Del Arte de Memoria») y XXII («Sobre el Arte de Raymundo Lulio»), instrumente el golpe definitivo a los restos del pensamiento mágico, desterrando a la mnemotecnia del lugar desorbitado en que la habían situado sus cultivadores en España, no recordará siquiera a este Francisco Antonio Artiga. Texto que, sin embargo, seguirá testimoniando obstinadamente, a través de sus múltiples reediciones en el siglo XVIII, la credibilidad firme en una técnica hacía ya mucho tiempo expulsada del corpus modélico de la retórica.

Como tributo a la combinatoria alfabética, escribe Artiga:

Sólo digo que si atiendes, toda la universal ciencia divina, y humana, se escribe sólo con veinte y dos letras. (pág. 412). 